\title{
Limiting Compatibility in Two-sided Markets
}

\author{
CHUN-HUI MIAO* \\ Department of Economics, University of South Carolina
}

\begin{abstract}
In two-sided markets where the platform is composed of a set of components, a monopolist may have an incentive to foreclose competition in the complementary market. By introducing incompatibility, the monopolist can exclude its complementors, thereby capturing surplus from both sides of customers. This type of behavior lowers social welfare. Private contracts such as a payment for compatibility can help restore efficiency, but its effectiveness depends on the form of the contract. The model's relevance to Microsoft's controversial practice of extending industry standards with proprietary capabilities is discussed.
\end{abstract}

\section{Introduction}

In recent years there has been a surge of interest in two-sided markets, where pairs of end users trade through a platform. Interesting economic issues arise because there are crossgroup externalities, the benefits enjoyed by users on one side depend on how well the platform does in attracting users on the other side. In the by now standard framework first explored by Caillaud and Jullien (2003), Rochet and Tirole (2003), and Armstrong (2006), a platform is treated as a single good controlled by a single entity.

However, in many industries characterized by two-sidedness, the platform through which users on two sides interact is composed of two components supplied by different producers (called complementors). ${ }^{1}$ In order to trade, users on one side must buy component $A$ that is compatible with component $B$ owned by users on the other side, but the two components may not come from the same producer. This raises interesting questions about a producer's incentive to provide compatibility within a platform, i.e., the compatibility of its product with its complementors'.

In this paper, we consider the incentive of a monopolist of component $A$ to provide compatibility between component $A$ and an independent supplier's component $B$ when users on

1705 College St., Columbia, SC 29208, USA. E-mail: miao@moore.sc.edu. This paper was previously circulated under the title "Compatibility in Two-Sided Markets". I am grateful to Melayne McInnes, Michael Waldman, Gianmaria Martini, to seminar participants at the University of Georgia, the 2008 International Industrial Organization Conference and the 2008 Econometric Society Summer Meeting, to the Editor and especially an anonymous referee for helpful comments and suggestions. All remaining errors are mine.

1 For example, in both television and radio broadcasting, viewers/listeners buy receivers and stations buy transmitters; in telecommunication, users buy telephones/modems and service providers buy terminals; in ecommerce, consumers use web browsers and stores employ web servers. 
two sides make independent purchase decisions. In contrast to the standard result obtained in an one-sided market, we show that the monopolist may find it profitable to tie the use of component $A$ with its own component $B$ in order to capture surplus from both sides of users. More specifically, when it narrows the technology gap with the independent supplier, the monopolist will limit the compatibility between component $A$ and its complementor's component $B$, thereby eliminating the competition. We then consider whether private contracts such as a payment for compatibility can lead to a more efficient outcome. We find that the answer depends on the form of the contract: whereas a royalty payment can always restore efficiency, a fixed fee payment may fail; at the same time, consumer surplus is higher under a fixed fee contract.

The basic logic of our findings can be illustrated with a simple example. ${ }^{2}$ Consider a market that comprises Internet users and content providers. An Internet user uses a web browser to connect to a content provider through its web server. Each connection generates a surplus of 10. There is a single producer of web browsers, but two producers of web servers engaged in Bertrand competition. All production is costless. First suppose that an Internet user and a content provider can make joint purchase decisions and act as if they were a single customer. According to the "one monopoly rent" theorem, the web browser monopolist can capture the entire surplus by setting its price at 10 (the so-called price squeeze strategy) without ever entering the server business (Bowman, 1957; Ordover et al., 1985). Based on this argument, Chicago school scholars claim that a monopolist of one good would never find it worthwhile to tie in order to foreclose competition in the market of the complementary good.

However, the above argument has limited applicability if the Internet user and the content provider make independent purchase decisions, as is the case in reality. Unless the Internet user has full bargaining power, an unlikely scenario, an increase in the price of a web browser will not pass through into the terms of trade between the two parties. Suppose that they split the surplus from trade; then the maximum amount that an Internet user is willing to pay for a web browser is 5 . This means that the monopolist can no longer employ the price squeeze strategy to extract full surplus in the server market. As such, it may choose to integrate with a server producer and monopolize the server market in order to capture monopoly rents.

Not only does it have the incentive to monopolize the server market, but it also has the necessary means to accomplish this end: through its control over the interface, it can change the compatibility of its web browser with the rival server. In the most extreme case, it can lock its rival out of the market completely by making its browser incompatible with the rival server, essentially tying the sales of a web browser with its own server.

This tie-in strategy, however, is inefficient when the monopolist owns an inferior server and reduces an Internet user's willingness to pay for the web browser. It may therefore be more profitable for the monopolist to accommodate the rival when the latter's technology is far superior but employ the tie-in strategy after it narrows the technology gap. Hence, the monopolist may adopt different strategies while improving its technology, thus giving rise to the type of phased responses that Microsoft is alleged to engage in. ${ }^{3}$

The remainder of the paper is organized as follows: Section 2 reviews related literature. Section 3 presents the basic setup. In Section 4, we analyze the benchmark case, in which

\footnotetext{
2 This example is chosen for its familiarity that most readers may have with, but is not necessarily most relevant to the model implications. Please see Section 5 for two applications of our model.

3 See Section 5 for more details on Microsoft's strategy.
} 
a single buyer purchases both components of a system. In Section 5, we analyze the case in which two buyers make uncoordinated purchases of system components. We find that the monopolist has an incentive to foreclose competition in the complementary market by introducing incompatibility and this lowers social welfare. In Section 6, we consider several extensions of the model and discuss whether contracts such as a payment for compatibility can restore efficiency. Section 7 concludes. Any formal proofs omitted from the main text are contained in the appendix.

\section{Related literature}

In addition to the articles mentioned earlier, this paper is related to many lines of research. In a seminal paper, Katz and Shapiro (1985) examine firms' incentives to produce compatible systems in the presence of network externalities. They find that firms with a large installed base will tend to be against compatibility, even when welfare is increased by the move to compatibility. Their main concern is the compatibility between competitors, but ours is the compatibility with a complementor. More closely related to our paper is the "mix and match" literature (Matutes and Regibeau, 1988, 1992; Economides, 1989), where each consumer buys all components of a complete system. It has been shown that firms competing on equal terms have an incentive to produce compatible components because this softens price competition between systems. In addition to reaching an opposite conclusion, these papers deal with compatibility in a one-sided market setting.

More recently, there have been a number of papers that address compatibility in twosided markets. Doganoglu and Wright (2006) focus on the impact of multi-homing. In their model, firms can coordinate on the choice of compatibility, but multi-homing weakens competition and reduces firms' incentive to achieve compatibility. Carrillo and Tan (2006) explicitly model the role of complementors in platform competition. They find that a platform and its complementors always benefit from an increase in the number of compatible complementors. Casadesus-Masanelly and Ruiz-Aliseda (2008) examine platform owners' competitive behavior under various compatibility regimes and derive a rich set of predictions about the equilibrium prices and profits. Orman (2008) studies the effects of compatibility on competition between proprietary and open two-sided platforms and shows that compatibility may increase profits for the proprietary platform. All these papers focus on compatibility between platforms and are mostly concerned with firms' pricing behavior while taking the compatibility regime as given (or as a joint decision by all firms involved).

Goldfain and Kovac (2007) (hereafter GK) examine the choice of compatibility between subsequent generations of the same platform in two-sided markets. They explore how a platform owner's choice of compatibility depends on the characteristics of the market and features of the new technology. In a setting similar to our model, Genakos, Kühn and Van Reenen (2007) (hereafter GKV) study compatibility between clients and servers, but they focus on workgroup purchases, where the same user buys both clients and servers. These two papers differ from ours in the role of compatibility. In GK, the choice of compatibility is driven by the trade-off between incentives of the new customers on one side of the market and the incentives of the installed base on the other side of the market; in GKV, the motive for limiting compatibility is price discrimination in the monopolized market, whereas in our model incompatibility is used to capture surplus in a complementary market.

Following the seminal contribution by Whinston (1990), a number of papers (Choi and 
Stefanadis 2001; Carlton and Waldman, 2002, 2006) demonstrate the use of tying to extend a firm's monopoly power from one market to another, but all these analyses have focused on a single buyer who purchases both components of a system. ${ }^{4}$ These models also rely on the entry deterrence effect of tying, whereas in our model the monopolist uses tying to exclude its rival even if the entry cost is zero. ${ }^{5}$ Gans (2007) and Carlton, Gans and Waldman (2007) show that tying can be profitable even in the absence of entry and exit. The case that they consider involves a reversible tie. They find that such a tie allows a monopolist to extract surplus from a rival producer of the complementary product. Since the tie is reversible, their models show perfect compatibility between rival firms' complementary products.

Choi (2006) also analyzes the effects of tying on competition in two-sided markets. His model, however, is concerned with the tying of a platform with a related product, not the tying of complementary components of a platform. In his model, tying induces more consumers to multi-home and makes platform specific exclusive content available to more consumers, while in ours tying reduces consumer choices. Amelio and Jullien (2007) focus on situations where optimal pricing implies subsidies on one side of the market. They show that tying may be used to relax the non-negativity constraint on prices. As a result, tying can overcome coordination failure in two-sided markets and benefit consumers in the case of a monopoly platform.

\section{Basic Setup}

In the type of markets we study here, there are two groups of agents, a measure 1 of group $A$ agents and a measure 1 of group $B$ agents. Agents from different groups can trade between each other and divide the gains from trading according to some exogenous bargaining mechanism, with a group $A$ agent obtaining a proportion $(1-s)$ of the surplus and a group $B$ agent obtaining $s$.

To participate in trade, a group $A$ agent must buy a unit of component $A$ and a group $B$ agent must buy a unit of component $B$. This assumption distinguishes our model from existing models of two-sided markets, which assume that agents on the two sides are served by unitary platforms.

Component $A$ is supplied by a single firm and there is no potential entry, but component $B$ are supplied by two firms, with $B_{1}$ from the monopolist of component $A$ and $B_{2}$ from an independent supplier. The quality of component $B$ as well as its compatibility with component $A$ determines the gain from trading between the two groups of agents. Specifically, each transaction between a group $A$ agent and a group $B$ agent generates a surplus of $d_{i} v_{i}$ for $i=1,2$, where $d_{i} \in[0,1]$ is the degree of compatibility between component $B_{i}$ and component $A$, and $v_{i}$ corresponds to the quality of component $B_{i}{ }^{6}$ Following Carlton and Waldman $(2002,2006)$, we assume that the independent supplier's component $B$ is of higher

\footnotetext{
4 Other papers including Carbajo, De Meza, and Seidman (1990), Chen (1997) and Nalebuff (2004) focus on the case of tying independent goods.

5 A more detailed comparison is made in Section 5.

6 We allow for partial compatibility because it is not a priori that the monopolist will only choose $d=0$ or $d=1$. Consider a slight decrease in $d$ in the neighborhood of 1: while it lowers the price of component $A$, it also increases the monopolist's market share in component $B$ so the net effect on its profit is ambiguous without further analysis. In reality, there are also situations where the performance of a system is degraded, but not completely damaged, by the mismatch between components.
} 
quality than the monopolist's component $B$, i.e., $v_{2}>v_{1} \cdot{ }^{7}$ Besides the quality difference, the two suppliers of component $B$ are also differentiated horizontally in the Hotelling fashion. Specifically, group $B$ agents are uniformly distributed on a line $[0,1]$ and that the two firms are located at the opposite ends of the line, with the monopolist at 0 and the independent supplier at 1 . A group $B$ agent incurs a transportation cost of $t l$ when buying from a supplier located at a distance of $l$. For ease of exposition, we assume that $t<v_{1} \min \left(\frac{1}{2}, s\right)$ so that markets are covered.

We assume that group $A$ agents are identical and each of them trades with all group $B$ agents (This is equivalent to assuming that each of them trades with exactly one agent in group $B$ but does not learn the type of group $B$ agent before purchasing component $A$.). ${ }^{8,9}$ Besides simplifying the analysis, this assumption ensures that the incentive to foreclose competition cannot be attributed to price discrimination. ${ }^{10}$ Therefore, a group $A$ agent's gross utility equals $U_{A}=(1-s) \sum_{i=1}^{2} d_{i} v_{i} x_{i}$, where $x_{1}$ (resp. $x_{2}$ ) is the market share of the monopolist (resp. the independent supplier) in component $B$, and a group $B$ agent's gross utility is $U_{B}=s d_{i} v_{i}-t x_{i}{ }^{11}$

We assume that the monopolist has control over the interface thus can costlessly manipulate the degree of compatibility, $d_{i}$, between component $A$ and component $B_{i},{ }^{12}$ but $v_{i}$ s are determined by firms' technology constraints and thus are exogenous to our model. Firms have the same production cost, normalized to zero. These assumptions, taken together, allow us to focus on the key issue, which is the monopolist's incentive to make its component compatible with its complementor's.

We consider the following game (see Figure 1): After the qualities of component $B$ by the two suppliers are realized, the monopolist chooses the degree of compatibility, $d_{2}$, between component $A$ and the independent supplier's component $B .{ }^{13}$ Subsequently, the two firms set the prices of component $B$, with the monopolist also setting the price of component $A$. Finally, agents in both groups make purchases. The solution concept we use is subgame perfect Nash equilibrium.

\footnotetext{
7 This assumption allows us to focus on the monopolist's incentive to foreclose a more efficient rival and facilitates comparison with existing models. The qualitative nature of the results would be unchanged if we assumed that consumers were indifferent between the monopolist's and the independent supplier's versions of component $B$, but the latter had a lower marginal cost of production.

8 In other words, the matching process between agents is taken as given. This is a standard approach used in many papers on two-sided markets (e.g., Rochet and Tirole, 2003; Armstrong, 2006). In Caillaud and Jullien (2003), platforms act as matchmakers but an agent's gross utility of joining a platform is also linear in the number of agents on the same platform.

9 In Section 6, we consider the case in which group $A$ agents are heterogeneous.

10 This assumption, however, limits the role played by network effects. See Section 7 for a discussion. Also see Genakos, Kühn and Van Reenen (2007) for an analysis, in which a monopolist limits interoperability and forecloses competition in order to price discriminate.

11 Since there is only one component $A$ available, the issue of multi-homing does not arise in this model.

12 Even if the independent supplier can manipulate compatibility by making investments, the cost of compatibility will depend on the amount of interoperability information supplied by the monopolist. Therefore, the monopolist can supply more or less interoperability information, which has the same effect as increasing or decreasing compatibility. In fact, whether Microsoft has abused its dominant position by refusing to supply interoperability information to potential competitors has been a central issue in the antitrust lawsuit brought by the European Commission (E.U. Commission Case COMP/C-3/37.792 Microsoft).

13 In Section 6, we show that it is never optimal for the monopolist to make its own component $B$ less than fully compatible with component $A$. In order to cut down the number of parameters of which we keep track, we use that result and let $d_{1}=1$.
} 


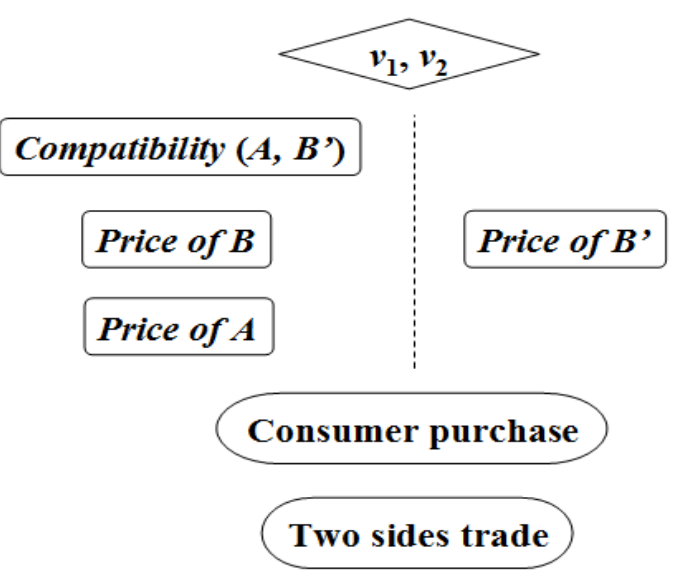

Figure 1: The Game

Throughout the paper, we denote by $p_{A}$ the price of component $A, p_{1}$ the price of component $B$ by the monopolist, $p_{2}$ the price of component $B$ by the independent supplier, $\pi$ the monopolist's total profits, and $\pi_{s}$ the independent supplier's profits.

Inability to Coordinate In our model setup, a crucial assumption is that end-users from two sides cannot coordinate their purchase decisions. This is true in most two-sided markets studied in the literature (Rochet and Tirole, 2003). It is also implicitly assumed that one side cannot subsidize the other side to make purchases. ${ }^{14}$ There are at least three reasons why this may be the case: first, interaction between end users may be anonymous. This is especially true in broadcast industries; second, even if end users are non-anonymous so their purchase decisions are observable, the side receiving the subsidy is still subject to a potential hold-up by the other side: after a group $A$ agent invests by purchasing component $A$, group $B$ agents may renege on the terms of trade; last, in a mass market with many end users, contracts used to coordinate purchases can be costly to implement and difficult to enforce.

\section{A Benchmark: Coordinated Purchases}

In order to see the role of two-sidedness played in our model, we begin with a benchmark analysis, in which an agent from group $A$ and an agent from group $B$ can jointly decide which combination of component $A$ and $B$ to buy, or equivalently, the same user buys both components.

In this analysis, since prices are set simultaneously, when $d_{2}>>v_{1} / v_{2}$ (see the proof of Proposition 1 for details), only the independent supplier sells component $B$. Given this, there is a continuum of equilibrium outcomes with $\left(p_{A}, p_{1}, p_{2}\right)$ such that $p_{A}+p_{2}=d_{2} v_{2}-t$ and $p_{2}-p_{1}<d_{2} v_{2}-v_{1}-t$ in the pricing subgame. The difference between the equilibria is the division across the two firms of the surplus associated with the independent supplier's superior complementary product. While it is typically assumed in the literature that firms share the surplus (Choi and Stefanadis, 2001; Carlton and Waldman, 2002), here we assume

\footnotetext{
14 This implies that there is no direct payments between end users. This is a commonly made assumption in models of two-sided markets, including the canonical model introduced by Rochet and Tirole (2006).
} 


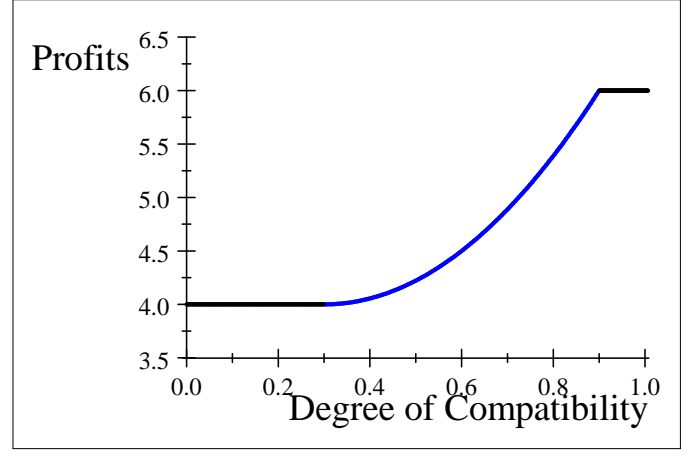

$v_{1}=5 t, v_{2}=10 t$ and $s=2 / 3$.

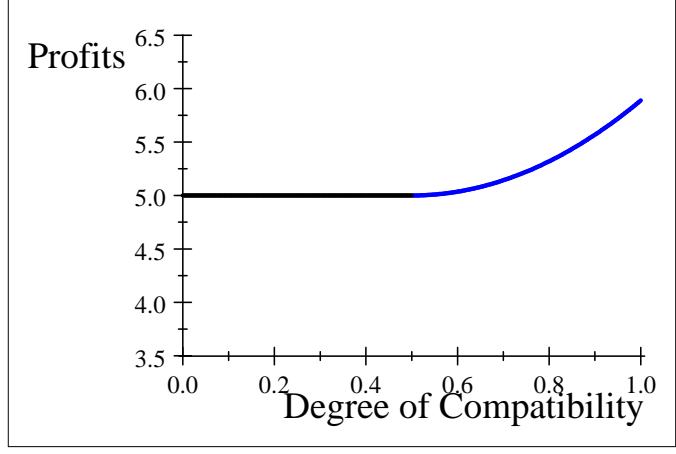

$v_{1}=6 t, v_{2}=8 t$ and $s=2 / 3$.

Figure 2: The monopolist's profit as a function of $d_{2}$ when consumers make coordinated purchases

that the independent supplier captures the entire surplus. It is not difficult to see that allowing the monopolist to share some of the efficiency gain will only strengthen our result.

Proposition 1 If an agent from group $A$ and an agent from group $B$ can jointly decide which combination of component $A$ and $B$ to buy, then the monopolist always makes component $A$ compatible with its complementor's component $B$.

Figure 2 depicts the monopolist's profit function when agents on two sides can make coordinated purchases. If $d_{2}$ is chosen such that both firms are active in the market for component $B$, then the monopolist's total profit is the convex segment in the middle. If one firm covers the entire market of $B$, then the monopolist's total profit is a flat segment at either end. From the graph, it is easy to see that the monopolist's total profit is maximized when $d_{2}=1$, which implies full compatibility. On the left panel, only the independent supplier sells component $B$; on the right, the two firms share the market for component $B$.

The benchmark analysis replicates the well known Chicago school argument, namely, the monopolist of one good never finds it worthwhile to monopolize the complementary good. By selling its own component $B$ at a low price and simultaneously raising the price of component $A$, the monopolist can exercise a price squeeze against the independent supplier and capture the entire monopoly profit. In addition, since the independent supplier sells a differentiated product, its presence increases the variety of component $B$ and makes component $A$ more valuable to customers, helping the monopolist's profitability. ${ }^{15}$ Therefore, the monopolist has no incentive to exclude its complementor.

It should be noted that consumers form a one-sided market when the two sides make coordinated purchases and this is why the Chicago school argument applies in the above analysis. However, the logic in an one-sided market do not always extend to two-sided markets, as shown below in our model.

\footnotetext{
15 In the Hotelling model, product variety reduces the distance that (some) consumers have to travel.
} 


\section{The Main Result: Uncoordinated Purchases}

In a two-sided market, agents on two sides make independent purchase decisions. A lower price in component $B$ does not increase a group $A$ agent's willingness to pay for component $A$. Thus the monopolist cannot extract consumer surplus from group $B$ agents by simply raising the price of component $A$. In order to earn monopoly profits, it may therefore have an incentive to foreclose competition in the market for component $B$ by limiting the compatibility between component $A$ and its complementor's component $B$.

Proposition 2 Social welfare is maximized at $d_{2}=1$; but if agents from two groups make independent purchase decisions and $s>3 t / 2 v_{2}$ then there always exists $\gamma_{0}<1$ such that the monopolist chooses $d_{2}=1$ when $v_{1} / v_{2}<\gamma_{0}$ and $d_{2}=0$ when $v_{1} / v_{2}>\gamma_{0}$.

According to Proposition 2, when the monopolist advances its technology in producing the complementary good, it moves away from supporting the rival technology: when the technology gap is big (i.e., $v_{1} / v_{2}$ is small), it is highly inefficient to exclude the more advanced producer of component $B$, so the monopolist embraces the rival technology by making component $A$ compatible with the independent supplier's component $B$ and extracts surplus through its monopoly in component $A$. Once the technology gap narrows, the monopolist starts to compete for market share of component $B$, since its ability to extract profits through selling component $A$ is constrained. It does so by modifying the interface to inject incompatibility with the rival product, effectively tying the sales of component $A$ with its own component $B$.

Figure 3 depicts the monopolist's profit function when agents on two sides make independent purchase decisions. It is maximized at either $d_{2}=0$ or $d_{2}=1$. It also increases with $v_{1} / v_{2}$, but the increase in $v_{1} / v_{2}$ has a greater impact when $d_{2}=0$. Therefore, $d_{2}=0$ maximizes profits when $v_{1} / v_{2}$ is sufficiently large.

It is not difficult to see why the result obtained in Proposition 1 does not carry over to a two-sided market: ${ }^{16}$ when agents on two sides make independent purchase decisions, the price squeeze strategy breaks down. Consumers' inability to coordinate prevents the monopolist to use price squeeze in two ways: first, since group $A$ agents only care about their share of the surplus from trading, raising the price of component $A$ cannot restore the monopolist's ability to extract surplus from group $B$ consumers; second, in a two-sided market, the volume of transaction depends not only on the price level, but also on the price structure. Hence, even if the total price remains constant, a higher price in component $A$ can negatively affect the volume of trade. In fact, in the above model, because of consumer homogeneity, raising the price of component $A$ can potentially lead to a market collapse. ${ }^{17}$

\footnotetext{
16 Our result is in addition to the eight basic fallacies discussed by Wright (2004) that can arise from using conventional wisdom from one-sided markets in two-sided market settings. Also see Evans (2003), which focuses on antitrust concerns.

17 For a less extreme example, we can consider the following: suppose that group $B$ agents are identical, but group $A$ agents differ in their gain from trading so the number of component $A$ buyers and thus the volume of trade is continuous in the price of component $A$. More specifically, a group $A$ agent enjoy a surplus of $v$ when trading with a group $B$ agent when the latter uses $B$ but a surplus of $v+\Delta$ when the latter uses $B^{\prime}$, where $v$ is distributed on $[a, b]$. If consumers can coordinate their purchases, then the monopolist has no reason to exclude its complementor, because doing so will reduce the price it can charge for its component $A$. But if consumers cannot coordinate, because of Bertrand competition, then the price of component $B$ will be driven to cost. The monopolist of component $A$ has no way to extract surplus from group $B$ agents, since any price change in
} 


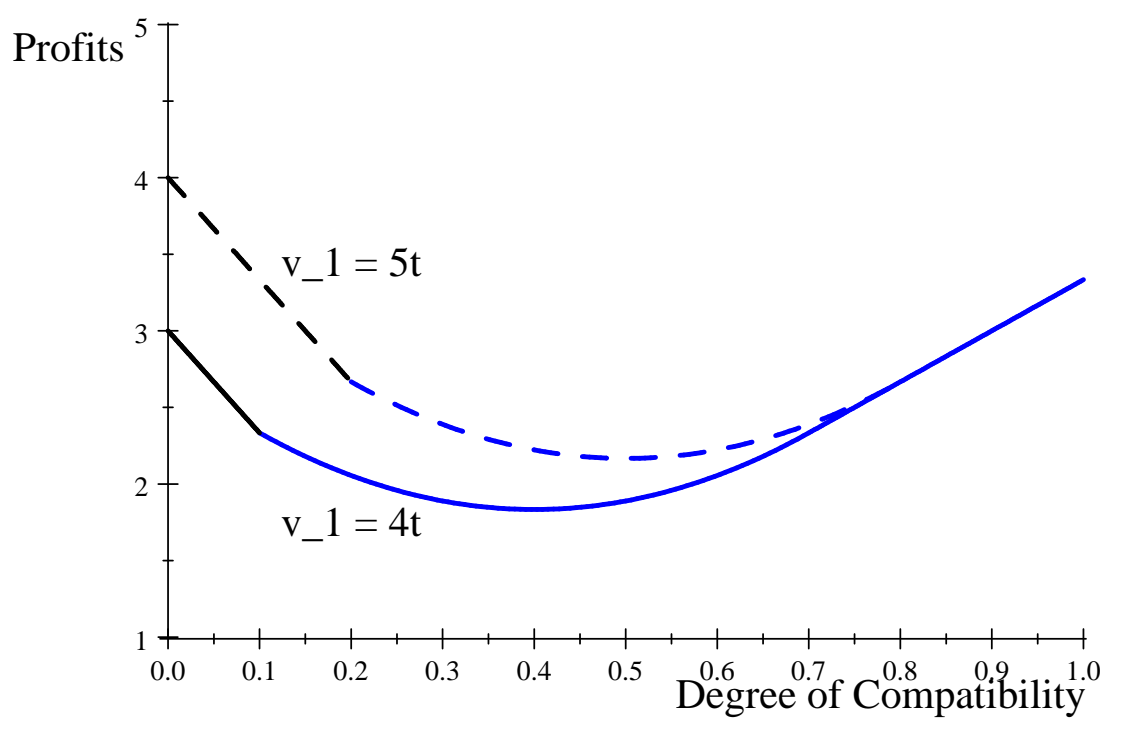

Figure 3: The monopolist's profit as a function of $d_{2}$ when consumers make uncoordinated purchases, with $s=2 / 3, v_{2}=10 t$ and $v_{1}=4 t$ or $5 t$

The above result contrasts with that of Whinston (1990), which shows under a wide variety of conditions that a monopolist cannot gain from tying complementary products used in fixed proportions. The key difference is the cross-group externality inherent in a twosided market setting. Note that tying is not profitable if group $B$ agents can make a side payment to group $A$ agents, in which case the monopolist only needs to raise the price of component $A$ in order to extract surplus from group $B$ agents. In our benchmark case, no such "bribe" is necessary because the purchase decision is jointly made; but in cases where they are separately made the monopolist can extract surplus from group $B$ agents only by excluding its rival. In this regard, our paper is most similar to Carlton and Waldman (2006), which considers a durable-goods monopolist's incentive to tie. They find that foreclosing a more efficient supplier allows the monopolist to extend its market power to the aftermarket and capture profits from consumers who purchase upgrades. In both papers, the monopolist abuses its market power in the tying market to pursue profits in the tied market and denies consumers access to a superior product. However, the two models have different predictions on how the independent supplier's technology advantage affects the monopolist's incentive to foreclose: in their model, the incentive is stronger when the independent supplier enjoys a clear technology advantage, but in ours it is stronger when the technology gap narrows. This difference is non-trivial and has important welfare implications. Their result, absent other considerations, suggests a basis for more vigorous antitrust enforcement, ${ }^{18}$ but our model finds that inefficient tying occurs only when the loss from it is relatively small, and therefore the gains from potential regulatory interventions are also small.

component $A$ will cause the firm to deviate from the profit maximizing price in component $A$, while leaving it the same profit (zero) from selling component $B$. Also see Section 6 for a related discussion.

${ }^{18}$ Nevertheless, the authors point out several caveat for the antitrust implications of their model and caution against the overzealous use of antitrust to attack tie-in sales. 
From the proof of Proposition 2, we can also see that the monopolist accommodates the independent supplier and shares the market for component $B$ when $s$ is small. The reason is easy to understand. Since $s$ is the share of surplus gained by group $B$ agents, a small $s$ implies that the profit that can be earned from component $B$ is relatively unimportant for the monopolist. Therefore it has a greater incentive to provide compatibility in order to increase group $A$ agents' willingnesses to pay.

It is perhaps worth noting that we obtain a unique equilibrium in Proposition 2, whose result does not require the use of a surplus sharing rule. The reason is that when a single agent buys both components, only the sum of the two prices matters and there are multiple ways to split the surplus between component $A$ and $B$ suppliers; but when agents on two sides make independent purchase decisions, the price of an individual component matters and this allows us to pin down the equilibrium prices of individual components.

Embrace, Extend and Extinguish The model just presented is relevant to a strategy called "Embrace, extend and extinguish" (EE\&E), allegedly used by Microsoft for entering product categories by first embracing widely used standards, then extending those standards with proprietary capabilities that work best with Windows Operating System (OS), and finally using those differences to extinguish the competition. ${ }^{19}$ While considerable amount of ink has been spent on Microsoft's various controversial practices, this strategy has attracted relatively little attention in the academic literature. ${ }^{20}$ Our model provides a plausible explanation for this strategy. Here we use Microsoft's implementation of Kerberos, a web security standard, as an example to illustrate its relevance to our model. ${ }^{21}$

Web transactions require the interaction between clients and servers. One can think of a client as component $A$ and a server as component $B$ in our model. Microsoft Windows enjoys a near monopoly in the market of client operating systems, but competes with the Unix OS in the market of servers. Since clients and servers are often bought by different parties, ${ }^{22}$ Microsoft has an incentive to extend its monopoly into the server market. By most accounts, the Unix server OS is superior to Windows, especially before Microsoft released the Windows 2000 server. Therefore Microsoft initially "embraced" Kerberos, the standard technology used to connect clients to servers running Unix operating systems, meaning that Microsoft Windows clients can connect to Unix servers via Kerberos. But with its new and improved operating system, Windows 2000, Microsoft "extended" Kerberos by taking advantage of an undefined field in the specifications to store authorization data. Because Microsoft had not published those extensions, "no non-Microsoft server can utilize the security features of the PC [Windows client] operating system." (Parenthesis added) As a result, Microsoft gained significant market share in the server market.

19 This phrase has been loosely used to describe a dominant firm's strategy in many different context, some of which do not readily fit the two-sided market paradigm. This paper does not purport to explain all uses of this phrase/strategy.

${ }^{20}$ Bresnahan (2001) provides an informal analysis that focuses on the network effects theory. Gans (2007) relates "embrace and extend" to Microsoft's tying strategy, but appears to use the term to refer to a reversible tie, which implies compatibility between the Windows OS and other applications (also see Carlton, Gans and Waldman, 2007).

${ }^{21}$ The following discussion is adapted from "Deadly embrace", The Economist, March 30th, 2000 and "Microsoft's Kerberos shuck and jive", Dominic Gates, The Industry Standard, May 11th, 2000.

${ }^{22}$ For instance, students can access university resources by connecting their personal computers to servers, but their purchase decisions are independent of the university's. 
Another example involves Intuit, the maker of popular personal finance software program Quicken. ${ }^{23}$ OFX (Open Financial Exchange) is a standard for exchanging financial information for finance packages and is used for downloading information from financial institutions such as banks and brokerages. It was created by Intuit and its two small rivals, Checkfree and Microsoft. Soon after, Intuit introduced its own implementation of the OFX format, called QFX, which are identical to OFX files, except that a small header is added to the file that identifies the financial institution where the data originated. While use of OFX is free, financial institutions are required to pay a licensing fee to Intuit if they wish to allow their customers the ability to download financial data in the QFX format.

It should be noted, however, many details in these cases are not captured by our simple model, and so, no claim is made to explain fully the observed behavior. Rather, the cases are used to illustrate the empirical relevance of our model and provide motivation for studying the composition of a platform. ${ }^{24}$

\section{Discussion}

In this section, we consider several extensions of the basic model.

\subsection{Compatibility with Own Components}

In the model, we take the degree of compatibility between the monopolist's own components $A$ and $B$ as given and assume that $d_{1}=1$. Readers may wonder whether the monopolist has an incentive to choose $d_{1}<1$. This question is non-trivial: by committing to a lower compatibility with its own component $B$, the monopolist may be able to induce the independent supplier to raise its price of component $B$ thereby relaxing competition. However, we can easily verify in the proof that the monopolist's total profits increase with $v_{1}$ in all cases. This means that any $d_{1}$ smaller than 1 cannot be the optimal choice, since it is equilivalent to reducing $v_{1}$ but keeping $d_{1}$ at 1 . Therefore our assumption that $d_{1}=1$ is without loss of generality. Intuitively, limiting compatibility between the two components makes both of them less attractive to buyers and the combined negative effects dominate the potential gain from relaxed competition in the market of one component.

\subsection{Consumer Heterogeneity}

We assume above that group $A$ agents are identical. ${ }^{25}$ This assumption is not critical to our result. In fact, our result grows stronger if group $A$ agents differ in their willingness

\footnotetext{
23 Intuit's Quicken owns a 70\% market share in the personal finance software market. (http://www.usatoday.com/educate/college/careers/Advice/1-16-06.htm)

24 The following quote is perhaps telling. In it, a Microsoft manager talks about its strategy against Netware, its main competitor in the work group server market:
}

In fact, I am still of the opinion that we will not really deliver a really telling blow against Netware until we make some user-visible, client-side feature that Netware will have trouble matching in their servers...By controlling the client, we also control the servers. "Netscape as Netware", Paul Maritz, Government Exhibit 498, http://www.usdoj.gov/atr/cases/exhibits/498.pdf.

25 We are grateful to an anonymous referee for suggesting the following analysis. 
to pay for component $A .{ }^{26}$ To see this, we assume that group $A$ agents have an outside option, but their values of the outside option differ (e.g. some of the television buyers own a radio, while others do not.). More specifically, a group $A$ agent's gross utility is $U_{A}=$ $(1-s) \sum_{i} d_{i} v_{i} x_{i}-u$, where $u$ is a random variable that represents the agent's outside option value.

If the monopolist sets $d_{2}=1$, then $U_{A}=(1-s)\left[v_{1} x_{1}+v_{2}\left(1-x_{1}\right)\right]-u$; but if $d_{2}=0$, then $U_{A}=(1-s) v_{1}-u$. Since a group $B$ agent's purchase decision is based only on the prices of component $B$, the distribution in consumer valuation and the resulting price change in component $A$ does not affect how the market share of component $B$ is determined. This means that $x_{1}$ does not depend on how $u$ is distributed and that $(1-s)\left(v_{2}-v_{1}\right)\left(1-x_{1}\right)$ is the upper limit on the monopolist's profit loss in the market for component $A$ when she switches from $d_{1}=1$ to $d_{2}=0$. By noting that the upper limit is reached if $u$ is a constant, we can conclude that, relative to the homogeneous consumers case, the monopolist may have a stronger incentive to limit compatibility with the independent supplier if group $A$ agents differ in their willingness to pay for component $A$.

\subsection{Non-integrated Platform Owner}

Our model can also be extended to other market structures, where foreclosure is less of a concern. In a companion paper (Miao and Xiao, 2009), we study the choice of compatibility by a monopolist of component $A$, who does not compete in the market for component $B$. A surprising result from that paper is that the monopolist does not always provide full compatibility with its complementors. Limiting compatibility with some of the component $B$ suppliers can be both privately profitable and socially desirable. ${ }^{27}$

The underlying intuition is similar to the one discussed in this paper: group $B$ agents do not internalize the effects of their choices of component $B$ on group $A$ agents; between two choices of component $B$, group $A$ agents naturally prefer the high quality one, but group $B$ agents may choose the other because of its low price; by limiting compatibility with the low quality component $B$, the seller of component $A$ can induce more group $B$ agents to buy the high quality one thereby increasing the value that group $A$ agents can gain from trading with group $B$ agents.

\subsection{Payment for Compatibility}

Having shown that the monopolist has an incentive to introduce incompatibility and that this incompatibility may sometimes result in inefficiency, we now consider whether efficiency can be restored if the independent supplier can make a payment in exchange for compatibility. Our findings are two-fold: on one hand, a contractual agreement that restores efficiency always exists under a royalty scheme, but may not exist under a fixed fee; on the other hand, consumers are worse off with the use of a royalty as compared with the use of a fixed fee.

We assume that the monopolist sets $d_{2}=1$ if the independent supplier makes a payment, but $d_{2}=0$ otherwise. Furthermore, we suppose that the monopolist cannot commit not to

\footnotetext{
${ }^{26}$ Since the market for component $A$ is monopolized, group $A$ agents cannot differ in any other dimensions.

27 This is in contrast to Carrillo and Tan (2006), who find that a platform and its complementors always benefit from an increase in the number of compatible complementors. Our model basically shows that their result may not hold if the complementary goods are substitutes among themselves.
} 
compete with the independent supplier in the market for component $B$ after receiving the payment, possibly due to antitrust concerns.

Proposition 3 Firms agree upon a fixed fee payment for compatibility that restores social efficiency if and only if $v_{1} / v_{2}$ is not too big.

The logic for the finding in Proposition 3 is easy to understand: compatibility not only raises the independent supplier's profit but also promotes competition in the market for component $B$, but the existence of the independent supplier and the two-sidedness of the market limits the monopolist's ability to capture the gain enjoyed by group $B$ agents. Because of this positive externality on consumers, a contractual agreement between the two producers may fail.

Proposition 4 Firms can always agree upon a royalty payment or a two-part tariff for compatibility that restores social efficiency, but consumer surplus is lower when a royalty is used than when a fixed fee is used, ceteris paribus.

In the market of component $B$, the use of royalty has two effects: first, it raises the independent supplier's marginal cost; second, it entitles the monopolist to profit from its rival's sales and this reduces its incentive to compete for market share. Both contribute to an increase in the prices of component $B$. Thus, from the monopolist's point of view, royalty provides a more efficient means through which it can extract consumer surplus than foreclosure. Hence, agreeing to a royalty payment for compatibility is always mutually beneficial for the two firms. This means that royalty can restore efficiency in more general conditions than a fixed fee, albeit at a cost to consumers.

The comparison between royalty and fixed fee payments is not just a theoretical exercise. After finding its refusal to supply interoperability information in violation of the European antitrust law, the EU commission ordered Microsoft to significantly cut the royalty rate for a license granting access to such information. ${ }^{28}$ As a response, Microsoft dropped royalty and started to charge a flat fee. Our result partly explains EU commission's approach: chosen appropriately, a limit on the royalty rate can improve consumer welfare without causing inefficiency; but it also urges caution on following such an approach, since even in the absence of the usual investment incentive problem this approach can lead to refusal to license in certain circumstances.

In sum, while there may be grounds for intervention when policy makers place a great emphasis on consumer surplus, we find that inefficient outcomes can usually be avoided if firms are free to contract.

\section{Conclusion}

Most previous analyses of tying have focused on a single buyer who purchases both components of a system. In this paper, we study two-sided markets where customers on two sides make independent purchases of system components. We find that a monopolist has an

\footnotetext{
${ }^{28}$ It is important to note that, however, the European Commission appears to be more concerned with workgroup server markets, which can involve both coordinated and uncoordinated purchases. See Kühn and Van Reenen (2008) for an excellent overview of the most important economic issues raised in European Commission vs. Microsoft (2004).
} 
incentive to foreclose competition in the complementary market by introducing incompatibility. Excluding its complementor allows it to extract surplus from both sides of customers. This type of behavior lowers social welfare. While this observation suggests a potential role for policy interventions including a mandatory disclosure of interoperability information by platform participants, we find that the incentive to foreclose arises only when it causes relatively small harm and that private contracts such as a payment for compatibility may help restore the efficient outcome.

The main contribution of this paper might well be to underline the importance of explicitly modeling platforms as combinations of components. This approach allows us to derive results that are different from those in previous analyses of compatibility. At the same time, the model presented in this paper does not capture many features of the real world markets. First, we considered a static model in discussing a monopolist's choices of compatibility but the real world situation is inherently dynamic; second, to focus on the issue of compatibility, we assumed a simple demand structure and thus put aside the coordination problem that often arises in two-sided markets. Models that incorporate more realistic elements will be examined in future researches.

\section{References}

Amelio, A. and B. Jullien (2007) "Tying and Freebies in Two-Sided Markets.” IDEI Working Papers 445, Institut d'Économie Industrielle (IDEI), Toulouse.

Armstrong, M. (2006) "Competition in two-sided markets." RAND Journal of Economics, 37(3): 668-691.

Armstrong, M. and J. Wright (2007) "Two-sided markets, competitive bottlenecks and exclusive contracts." Economic Theory, 32: 353-380.

Bowman, W. S. J. (1957) “Tying arrangements and the leverage problem.” Yale Law Journal, 67: 19-36.

Bresnahan, T. (2001) "Network effects and microsoft.” SIEPR Discussion Paper No. 00-51.

Bresnahan, T. (2002) "The economics of the microsoft case.” Mimeo. Stanford University.

Caillaud, B. and B. Jullien (2003) "Chicken and egg: Competition among intermediation service providers." Rand Journal of Economics, 34: 309-328.

Carbajo, J., D. deMeza and D. Seidman (1990) "A strategic motivation for commodity bundling." Journal of Industrial Economics, 38: 283-298.

Carlton, D., J. Gans and M. Waldman (2007) "Why tie a product consumers do not use?" NBER Working Paper, No. 13339.

Carlton, D. W. and M. Waldman (2002) "The strategic use of tying to preserve and create market power in evolving industries." Rand Journal of Economics, XXXIII: 194-220.

Carlton, D. W. and M. Waldman (2006) "Tying, upgrades, and switching costs in durablegoods markets.” NBER Working Paper No. 11407. 
Carrillo, J. and G. Tan (2006) "Platform Competition: The Role of Multi-homing and Complementors." NET Institute Working Paper No 06-30.

Casadesus-Masanell, R., F. Ruiz-Aliseda and R. Fargas (2009) "Platform competition, compatibility, and social efficiency.” NET Institute Working Paper No. 08-32.

Chen, Y. (1997) “Equilibrium product bundling.” Journal of Business, 70: 85-103.

Choi, J. P. (2006) “Tying in Two-Sided Markets with Multi-Homing.” NET Institute Working Paper No. 06-04.

Doganoglu, T. and J. Wright (2006) "Multihoming and compatibility." International Journal of Industrial Organization, 24: 45-67.

Economides, N. (1989) "Desirability of compatibility in the absence of network externalities.” American Economic Review, 79: 1165-81.

Evans, D. (2003) “The Antitrust Economics Of Multi-sided Platform Markets." Yale Journal on Regulation, 20: 325-431.

Gans, J. (2007) "Remedies for Tying in Computer Applications.” Gans, J. S., 2007, ŚRemedies for Tying in Computer Applications $\breve{S}$, The Selected Works of Joshua S Gans. http://works.bepress.com/joshuagans/13.

Genakos, C., K. Kühn and J. Van Reenen (2007) "The incentives of a monopolist to degrade interoperability: Theory and evidence from PCs.” CEPR Working Paper.

Goldfain, K. and E. Kovac (2007) “On Compatibility in Two-Sided Markets.” Mimeo, University of Bonn.

Katz, M. L. and C. Shapiro (1985) "Network externalities, competition, and compatibility." American Economic Review, 75: 424-40.

Kuhn, K. and J. Van Reenen (2008) "Interoperability and market foreclosure in the European Microsoft case.” Centre for Economic Performance, Special Paper No. 20.

Matutes, C. and P. Regibeau (1988) "'mix and match": Product compatibility without network externalities." Rand Journal of Economics, 19: 221-34.

Matutes, C. and P. Regibeau (1992) "Compatibility and bundling of complementary goods in a duopoly.” Journal of Industrial Economics, 40: 37-54.

Miao, C.-H. and G. Xiao (2009) "Compatibility with complementors in two-sided markets." Working Paper, University of South Carolina.

Nalebuff, B. (2004) "Bundling as an entry barrier." The Quarterly Journal of Economics, 119: 159-187.

Ordover, J. A., A. O. Sykes and R. D. Willig (1985) "Nonprice anticompetitive behavior by dominant firms toward the producers of complementary products." Antitrust and Regulation: Essays in Memory of John J.McGowan, 115-30. 
Orman, W. (2008) "The Effects of Compatibility on Competition between Proprietary and Open Two-Sided Platforms.” Working Paper, University of Alabama in Huntsville.

Rochet, J. and J. Tirole (2006) "Two-sided markets: A progress report." RAND Journal of Economics, 37: 645-667.

Rochet, J. C. and J. Tirole (2003) "Platform Competition in Two-Sided Markets." Journal of the European Economic Association, 1: 990-1029.

Whinston, M. D. (1990) “Tying, foreclosure, and exclusion.” American Economic Review, 80: 837-859.

Wright, J. (2004) “One-sided Logic in Two-sided Markets." Review of Network Economics, 3: $42-63$.

\section{Appendix}

\subsection{Proofs}

Proof of Proposition 1. First, if $d_{2}=0$, then only the monopolist sells component $B$. By the assumption that $v_{1} \geq 2 t$, the market is covered and $\pi=v_{1}-t$.

Second, if $d_{2}>0$, then there are three cases:

Case (i): $v_{1} / v_{2}-d_{2} \in\left[-4 t / v_{2}, 2 t / v_{2}\right]$. The two firms share the market for component $B$. We have $v_{1}-t x_{1}-p_{1}=d_{2} v_{2}-t\left(1-x_{1}\right)-p_{2}$. Hence the monopolist's market share is $x_{1}=1 / 2+\left[\left(v_{1}-d_{2} v_{2}\right)+p_{2}-p_{1}\right] / 2 t$ and $x_{1}^{\prime}\left(p_{1}\right)=-(2 t)^{-1}$. Since $p_{A}=v_{1}-t x_{1}-p_{1}$ and $\pi=$ $p_{A}+p_{1} x_{1}=v_{1}-t x_{1}-p_{1}\left(1-x_{1}\right)$, the monopolist's FOC is $\left[\left(v_{1}-d_{2} v_{2}\right)+p_{2}-2 p_{1}\right] / 2 t=0$, i.e., $p_{1}^{*}\left(p_{2}\right)=\left[p_{2}+\left(v_{1}-d_{2} v_{2}\right)\right] / 2$. Similarly, we can get $p_{2}^{*}\left(p_{1}\right)=\left[p_{1}+t-\left(v_{1}-d_{2} v_{2}\right)\right] / 2$. Solving, we obtain that $p_{1}^{*}=t / 3+\left(v_{1}-d_{2} v_{2}\right) / 3, p_{2}^{*}=2 t / 3-\left(v_{1}-d_{2} v_{2}\right) / 3, x_{1}^{*}=\left(v_{1}-d_{2} v_{2}\right) / 6 t+2 / 3$ and $\pi=v_{1}+\left(-14 t^{2}+4 t \Delta+\Delta^{2}\right) / 18 t$, where $\Delta=\left(d_{2} v_{2}-v_{1}\right) \cdot{ }^{29}$

Case (ii): $v_{1} / v_{2}-d_{2}>2 t / v_{2}$. From the analysis of case (i), we can see that the monopolist can make all sales of component $B$ by setting $p_{1} \leq\left(v_{1}-d_{2} v_{2}\right)-t$. At the same time, $p_{A}=v_{1}-t-p_{1}$. Hence the monopolist's total profit is uniquely determined and equals $v_{1}-t$. This is equivalent to having $d_{2}=0$.

Case (iii) $v_{1} / v_{2}-d_{2}<-4 t / v_{2}$. From the analysis of case (i), we can see that the independent supplier serves the entire market for component $B$ by setting $p_{2} \leq\left(d_{2} v_{2}-v_{1}\right)-$ $2 t$. Since buyers only care about $p_{A}+p_{2}$ and the two prices are set simultaneously, there is a continuum of equilibrium outcomes with $\left(p_{A}, p_{1}, p_{2}\right)$ such that $p_{2} \in\left[0,\left(d_{2} v_{2}-v_{1}\right)-2 t\right]$, $p_{A}=d_{2} v_{2}-t-p_{2}$ and $p_{1}=p_{2}+\left(v_{1}-d_{2} v_{2}\right)+t$. By our assumption that the independent supplier captures the entire surplus, we have $p_{2}=\left(d_{2} v_{2}-v_{1}\right)-2 t$ and $p_{A}=v_{1}+t$. Hence $\pi=v_{1}+t$. Note that if the monopolist shares part of the efficiency gain, then its profit will increases with $d_{2}$. It is also easy to verify that $\pi$ increase with $v_{1}$ in all above three cases.

Third, suppose that $d_{2}$ is chosen such that case (i) holds. Since $v_{1} / v_{2}-d_{2}<2 t / v_{2}$, $\partial \pi / \partial d_{2}=v_{2}\left[2 t-\left(v_{1}-d_{2} v_{2}\right)\right] / 9 t>0$, that is, the monopolist's profit increases with $d_{2}$. Therefore, it is maximized at either $v_{1} / v_{2}+4 t / v_{2}$ if $v_{1} / v_{2}+4 t / v_{2}<1$ or 1 if $v_{1} / v_{2}+4 t / v_{2} \geq$ 1 . But if $v_{1} / v_{2}+4 t / v_{2}<1$, then $\pi\left(d_{2}=v_{1} / v_{2}+4 t / v_{2}\right)=v_{1}+t$, equal to $\pi\left(d_{2}=1\right)$ in case

\footnotetext{
${ }^{29}$ If the two firms have a positive marginal cost in producing component $B$, then the two prices solved here correspond to the markups on costs.
} 
(iii). At the same time, it is never optimal to choose $d_{2}$ such that case (ii) holds, in which $\pi=v_{1}-t$. Therefore, $d_{2}^{*}=1$.

Proof of Proposition 2. I. On the monopolist's choice of compatibility. First, in the market for component $A$, we must have $p_{A}=(1-s)\left(v_{1} x_{1}+d_{2} v_{2} x_{2}\right)$.

Second, if $d_{2}=0$, then the market for component $B$ is monopolized by the monopolist. The monopolist's problem is $\max _{x_{1}} p_{1} x_{1}+p_{A}$, where $p_{1}=s v_{1}-t x_{1}, p_{A}=(1-s) v_{1} x_{1}$ and $x_{1} \leq 1$. Solving, since $v_{1}>2 t$, we get $x_{1}^{*}=1$ and $\pi=v_{1}-t$.

Third, if $d_{2}>0$, then there are three possibilities:

Case (i): $v_{1} / v_{2}-d_{2} \in\left[-3 t / v_{2}, 3 t / v_{2}\right]$. The two firms share the market for component $B$. We have $v_{1} s-t x_{1}-p_{1}=d_{2} s v_{2}-t\left(1-x_{1}\right)-p_{2}$. The monopolist's market share is $x_{1}=\frac{1}{2}+\left[s\left(v_{1}-d_{2} v_{2}\right)+p_{2}-p_{1}\right] / 2 t$. Hence, $x_{1}^{\prime}\left(p_{1}\right)=-1 / 2 t$. Since $\pi=p_{A}+p_{1} x_{1}$, the monopolist's FOC is $\partial \pi / \partial p_{1}=-\left((1-s)\left(v_{1} / v_{2}-d_{2}\right)+p_{1}\right) / 2 t+\left[s\left(v_{1}-d_{2} v_{2}\right)+p_{2}-\right.$ $\left.p_{1}\right] / 2 t+1 / 2=0$, i.e., $p_{1}^{*}\left(p_{2}\right)=\left[p_{2}+t+(2 s-1)\left(v_{1}-d_{2} v_{2}\right)\right] / 2$. Similarly, we can get $p_{2}^{*}\left(p_{1}\right)=\left[t+p_{1}+s\left(d_{2} v_{2}-v_{1}\right)\right] / 2$. Solving, we obtain that $p_{1}^{*}=t-(s-2 / 3)\left(d_{2} v_{2}-v_{1}\right)$, $p_{2}^{*}=t-\left(v_{1}-d_{2} v_{2}\right) / 3, x_{1}^{*}=1 / 2+\left(v_{1}-d_{2} v_{2}\right) / 6 t, \pi=\left(t+\left(v_{1}-d_{2} v_{2}\right) / 3\right)^{2} / 2 t+d_{2}(1-s) v_{2}$ and $\pi_{s}=\left(t-\left(v_{1}-d_{2} v_{2}\right) / 3\right)^{2} / 2 t$.

Case (ii): $v_{1} / v_{2}-d_{2}>3 t / v_{2}$. From the analysis of case (i), we can see that the monopolist makes all sales of component $B$ by setting $p_{1}=s\left(v_{1}-d_{2} v_{2}\right)-t$. In this case, $\pi=s\left(v_{1}-d_{2} v_{2}\right)-t+(1-s) v_{1}=v_{1}-s d_{2} v_{2}-t$ and it decreases with $d_{2}$. This means that $d_{2}$ should be set to 0 and $\pi=v_{1}-t$.

Case (iii) $v_{1} / v_{2}-d_{2}<-3 t / v_{2}$. Here $v_{1} / v_{2}$ is too small for the monopolist to compete with its rival, so it sells only component $A$ and obtains a profit of $(1-s) d_{2} v_{2}$, increasing in $d_{2}$. This means that $d_{2}$ should be set to 1 and $\pi=(1-s) v_{2}$. It is easy to verify that $\pi$ increase with $v_{1}$ in all above three cases.

Fourth, suppose that $d_{2}$ is chosen such that case (i) holds. It is easy to verify that $\pi$ is convex in $d_{2}$. Thus it is maximized at either $\max \left(0, v_{1} / v_{2}-3 t / v_{2}\right)$ or $\min \left(1, v_{1} / v_{2}+3 t / v_{2}\right)$. But if $v_{1} / v_{2}-3 t / v_{2}>0$, then $\pi\left(d_{2}=v_{1} / v_{2}-3 t / v_{2}\right)=v_{1}-t+s\left(3 t-v_{1}\right)<v_{1}-t=\pi\left(d_{2}=\right.$ $0)$ in case (ii), so $\left(v_{1}-3 t\right) / v_{2}$ never maximizes $\pi$. Similarly, we can rule out $\left(v_{1}+3 t\right) / v_{2}$.

Therefore, the optimal choice of $d_{2}$ is either 0 or 1 . If $d_{2}=0$, then $\pi=v_{1}-t$; if $d_{2}=1$, then $\pi=(1-s) v_{2}$ when $v_{1} / v_{2} \leq 1-3 t / v_{2}$, or $\left[t+\left(v_{1}-v_{2}\right) / 3\right]^{2} / 2 t+(1-s) v_{2}$ when $v_{1} / v_{2}>1-3 t / v_{2}$. This means that if (a) $s \geq 4 t / v_{2}$, then the optimal choice of $d_{2}$ is 0 iff $v_{1} / v_{2}>1-s+t / v_{2}$; and if (b) $3 t / 2 v_{2}<s<4 t / v_{2}$, then the optimal choice of $d_{2}$ is 0 iff $v_{1} / v_{2}>1-3 t\left(\sqrt{1+2 s v_{2} / t}-2\right) / v_{2}$. In case (a), the two firms never share the market for component $B$; in case (b), the two firms share the market for component $B$ if $1-3 t / v_{2}<v_{1} / v_{2}<1-3 t\left(\sqrt{1+2 s v_{2} / t}-2\right) / v_{2}$.

II. On social welfare. First, we find the total surplus in each of the three cases: case (i) $v_{1} / v_{2}-d_{2} \in\left[-3 t / v_{2}, 3 t / v_{2}\right]: T S=v_{1} x_{1}+d_{2} v_{2}\left(1-x_{1}\right)-\int_{0}^{x_{1}} t x d x-\int_{0}^{1-x_{1}} t x d x$, where $x_{1}^{*}=1 / 2+\left(v_{1}-d_{2} v_{2}\right) / 6 t$; case (ii) $v_{1} / v_{2}-d_{2}>3 t / v_{2}: T S=v_{1}-\int_{0}^{1} t x d x=v_{1}-t / 2$; case (iii) $v_{1} / v_{2}-d_{2}<-3 t / v_{2}: T S=d_{2} v_{2}-t / 2$.

Second, suppose that $d_{2}$ is chosen such that case (i) holds. It is easy to verify that $T S$ is convex in $d_{2}$. Thus it is maximized at either $\max \left(0,\left(v_{1}-3 t\right) / v_{2}\right)$ or $\min \left[1,\left(v_{1}+3 t\right) / v_{2}\right]$. But if $\left(v_{1}-3 t\right) / v_{2}>0$, then $T S\left(d_{2}=\left(v_{1}-3 t\right) / v_{2}\right)=v_{1}-t / 2<T S\left(d_{2}=v_{1} / v_{2}\right)=$ $v_{1}-t / 4$, so $\left(v_{1}-3 t\right) / v_{2}$ never maximizes $T S$. Similarly, we can rule out $d_{2}=0$, since $T S\left(d_{2}=0\right)=v_{1}-t / 2$. 
Third, if $\left(v_{1}+3 t\right) / v_{2}<1$, then $T S\left(d_{2}=\left(v_{1}+3 t\right) / v_{2}\right)=v_{1}+5 t / 2$, smaller than $T S\left(d_{2}=1\right)$ in case (iii); if $\left(v_{1}+3 t\right) / v_{2}>1$, then $T S$ is maximized at $d_{2}=1$.

Therefore, $d_{2}=1$ always maximizes social welfare.

Proof of Proposition 3. To prove it, we can focus on the case when $v_{1} / v_{2} \in\left[1-3 t / v_{2}, 1\right]$. In this case, both firms sell component $B$ when $d_{2}=1$.

First, the maximum payment for compatibility that the independent supplier is willing to make is its profit when $d_{2}=1$. According to the proof of Proposition $2, \pi_{s}=$ $\left(t-\left(v_{1}-v_{2}\right) / 3\right)^{2} / 2 t$. Since $\partial \pi_{s} / \partial\left(v_{1} / v_{2}\right)=-v_{2}\left(t-\left(v_{1}-v_{2}\right) / 3\right) / 3 t<0$, the independent supplier's willingness to pay for compatibility decreases with $v_{1} / v_{2}$.

Second, the monopolist is willing to provide compatibility only if the payment is at least $Y_{0}=\left(v_{1}-t\right)-\left(\left(t+\left(v_{1}-v_{2}\right) / 3\right)^{2} / 2 t+(1-s) v_{2}\right)$, where the first term on the right is the monopolist's profit when $d_{2}=0$ and the second term is its profit when $d_{2}=1$. It is easy to verify that $\partial Y_{0} / \partial\left(v_{1} / v_{2}\right)=\frac{1}{9} v_{2}\left(v_{2}-v_{1}+6\right)>0$, that is, the monopolist demands a greater payment for compatibility when $v_{1} / v_{2}$ increases.

Third, $\pi_{s}$ and $Y_{0}$ intersects at $v_{1} / v_{2}=1-s+t / v_{2}$. Since $s v_{1}>t, v_{1} / v_{2}<1$. This means that for all $v_{1} / v_{2} \in\left[\max \left(v_{1} / v_{2}, 1-3 t / v_{2}\right), 1\right]$ we must have $\pi_{s} \leq Y_{0}$, i.e., the monopolist's required payment exceeds the independent supplier's maximum willingness to pay for compatibility.

Proof of Proposition 4. Suppose that the monopolist chooses a two-part tariff $T=v_{2}(f+$ $r x_{2}$ ), where $x_{2}$ is independent supplier's market share. (A royalty payment corresponds to the case in which $f=0$.) We would expect a payment for compatibility to be agreed upon only if doing so raises the joint profits of the monopolist and the independent supplier (in which case they could split the gains in some fashion). Since the joint profits do not vary with $f$, we just need to find the profit-maximizing $r$ by solving the subgame in the competition stage.

Case i) $v_{1} / v_{2}>1-3 t / v_{2}$. We have $s v_{1}-t x_{1}-p_{1}=s v_{2}-t x_{2}-p_{2}$. Hence, $x_{1}^{\prime}\left(p_{1}\right)=$ $x_{2}^{\prime}\left(p_{2}\right)=-(2 t)^{-1}$ and $x_{1}^{\prime}\left(p_{2}\right)=x_{2}^{\prime}\left(p_{1}\right)=(2 t)^{-1}$. Since $\pi=p_{A}+p_{1} x_{1}+v_{2} r x_{2}$, where $p_{A}=\left(x_{1} v_{1} / v_{2}+x_{2}\right)(1-s) v_{2}$, the monopolist's FOC is $\partial \pi / \partial p_{1}=-\left[\left(v_{1} / v_{2}-1\right)(1-s) v_{2}+\right.$ $\left.p_{1}\right] / 2 t+\left[\left(v_{1}-v_{2}\right) s+p_{2}-p_{1}\right] / 2 t+1 / 2+v_{2} r / 2 t=0$, i.e., $p_{1}^{*}\left(p_{2}\right)=\left[p_{2}+t+\left(v_{1}-\right.\right.$ $\left.\left.v_{2}\right)(2 s-1)+v_{2} r\right] / 2$. Similarly, we can get $p_{2}^{*}\left(p_{1}\right)=\left[t+p_{1}+\left(v_{2}-v_{1}\right) s+v_{2} r\right] / 2$. Solving, we obtain that $p_{1}^{*}=t+r v_{2}-(s-2 / 3)\left(v_{2}-v_{1}\right), p_{2}^{*}=t+r v_{2}+\left(v_{2}-v_{1}\right) / 3, x_{1}^{*}=1 / 2+$ $\left(v_{1}-v_{2}\right) / 6 t, x_{2}^{*}=1 / 2+\left(v_{2}-v_{1}\right) / 6 t, \pi=\left[t+\left(v_{1}-v_{2}\right) / 3\right]^{2} / 2 t+(1-s+r) v_{2}$ and $\pi_{s}=\left[t-\left(v_{1}-v_{2}\right) / 3\right]^{2} / 2 t$. Since $\pi$ strictly increases with $r, r$ should be chosen such that $p_{2}^{*}+t x_{2}=s v_{2}$, i.e., $t+r v_{2}+\left(v_{2}-v_{1}\right) / 3=s v_{2}-t / 2-\left(v_{2}-v_{1}\right) / 6$. Hence we obtain $r=-\left(3 t+v_{2}-v_{1}-2 s v_{2}\right) / 2 v_{2}$. Thus the industry profit is $\pi=\left[t+\left(v_{1}-v_{2}\right) / 3\right]^{2} / 2 t+$ $(1-s) v_{2}-\left(3 t+v_{2}-v_{1}-2 s v_{2}\right) / 2+\left[t-\left(v_{1}-v_{2}\right) / 3\right]^{2} / 2 t$. It is easy to verify that it is always greater than $v_{1}-t$, the industry profit if no payment for compatibility is made.

Case ii) $v_{1} / v_{2} \leq 1-3 t / v_{2}$. In this case, only the independent supplier sells component $B$ and monopolist's profit again increases with $r$. Therefore, the industry profit will be $v_{2}-t>$ $v_{1}-t$.

From the above, we can see that firms' market shares in component $B$ do not vary with $r$, the royalty rate. Therefore, in order to compare consumer surplus, we only need to compare the prices of component $B$. Since their prices both increase with $r$, we can conclude that consumer surplus is higher if firms use a fixed fee payment. 


\subsection{Alternative Timing for Proposition 1}

Another way to avoid the multiple equilibria problem mentioned in the proof of Proposition 1 is to allow for sequential pricing. In the following, we prove that our result in Proposition 1 continues to hold in a sequential pricing game. Following Gans (2007), we consider the following pricing subgame: first, the monopolist sets the price of component $A$; second, consumers choose whether to purchase $A$ or not; third, the two firms simultaneously set the prices of component $B$; last, consumers choose which $B$ to purchase.

Proof. First, if $d_{2}=0$, then only the monopolist sells component $B$. By the assumption that $v_{1} \geq 2 t$, the market is covered and $\pi=v_{1}-t$.

Second, if $d_{2}>0$, then there are three cases:

Case (i): $v_{1} / v_{2}-d_{2} \in\left[-3 t / v_{2}, 3 t / v_{2}\right]$. The two firms share the market for component $B$. We have $v_{1}-t x_{1}-p_{1}=d_{2} v_{2}-t\left(1-x_{1}\right)-p_{2}$. Hence the monopolist's market share is $x_{1}=1 / 2+\left[\left(v_{1}-d_{2} v_{2}\right)+p_{2}-p_{1}\right] / 2 t$ and $x_{1}^{\prime}\left(p_{1}\right)=-(2 t)^{-1}$. The monopolist's FOC is $\left[t+\left(v_{1}-d_{2} v_{2}\right)+p_{2}-2 p_{1}\right] / 2 t=0$, i.e., $p_{1}^{*}\left(p_{2}\right)=\left[p_{2}+t+\left(v_{1}-d_{2} v_{2}\right)\right] / 2$. Similarly, we can get $p_{2}^{*}\left(p_{1}\right)=\left[p_{1}+t-\left(v_{1}-d_{2} v_{2}\right)\right] / 2$. Solving, we obtain that $p_{1}^{*}=t+\left(v_{1}-d_{2} v_{2}\right) / 3$, $p_{2}^{*}=t-\left(v_{1}-d_{2} v_{2}\right) / 3, x_{1}^{*}=\left(v_{1}-d_{2} v_{2}\right) / 6 t+1 / 2$. Hence $p_{A}$ can be set at $v_{1}-t x_{1}^{*}-p_{1}^{*}=$ $v_{1}-\left(v_{1}-d_{2} v_{2}\right) / 6-t / 2-t-\left(v_{1}-d_{2} v_{2}\right) / 3=\left(v_{1}+d_{2} v_{2}\right) / 2-3 t / 2$. Therefore, $\pi=$ $\left(v_{1}+d_{2} v_{2}\right) / 2-3 t / 2+\left[t+\left(v_{1}-d_{2} v_{2}\right) / 3\right]^{2} / 2 t$.

Case (ii): $v_{1} / v_{2}-d_{2}>3 t / v_{2}$. From the analysis of case (i), we can see that the monopolist can make all sales of component $B$ by setting $p_{1}=\left(v_{1}-d_{2} v_{2}\right)-t$. At the same time, $p_{A}=v_{1}-t-p_{1}$. Hence $\pi=v_{1}-t$. This is equivalent to having $d_{2}=0$.

Case (iii) $v_{1} / v_{2}-d_{2}<-3 t / v_{2}$. From the analysis of case (i), we can see that the independent supplier serves the entire market for component $B$ by setting $p_{2}=\left(d_{2} v_{2}-\right.$ $\left.v_{1}\right)-t$. Hence $p_{A}=d_{2} v_{2}-t-p_{2}=v_{1}$ and $\pi=v_{1}$.

Third, suppose that $d_{2}$ is chosen such that case (i) holds; it is easy to verify that $\pi$ is convex in $d_{2}, \pi\left(d_{2}=\left(v_{1}-3 t\right) / v_{2}\right)=v_{1}-t$ and $\pi>v_{1}-t$ for all $d_{2}>v_{1} / v_{2}$. This means that $\pi\left(d_{2}\right)$ is maximized at either $\left(v_{1}+3 t\right) / v_{2}$ if $\left(v_{1}+3 t\right) / v_{2}<1$ or 1 if $\left(v_{1}+3 t\right) / v_{2} \geq 1$. But if $\left(v_{1}+3 t\right) / v_{2}<1$, then $\pi\left(\left(v_{1}+3 t\right) / v_{2}\right)=v_{1}$, the same profit as that the monopolist can earn if $d_{2}$ is set to 1 such that case (iii) holds. At the same time, it is never optimal to choose $d_{2}$ such that case (ii) holds, in which $\pi=v_{1}-t$. Therefore, $d_{2}^{*}=1$. 